\title{
1. Introduction: accounting for risk in trade agreements
}

\section{David Robertson}

The WTO agreements extended the GATT principles of non-discrimination and transparency into new areas of international commerce, strengthening and clarifying trade rules and extending them to cover trade in agriculture and services, establishing new agreements on trade-related investment measures and intellectual property rights, and introducing an understanding on dispute settlement procedures. Subsequently, new objectives were added to meet developing countries' special interests, and trade and the environment. This enlargement of trade subject to international rules, however, has increased tensions among the WTO membership, which has reached 135, and generated trade disputes over interpretations of the complex new agreements. The Uruguay Round final act contains much bureaucratic language and many 'constructive ambiguities' to mask differences, all of which were necessary for a negotiated text to be agreed.

In fact, new tensions have surrounded the rapid growth in international trade and globalization in the past decade. The new WTO agreements were incomplete and some texts contained ambiguities which increased the scope for disputes among members and placed unexpected pressures on the new dispute settlement understanding. Moreover, the new dispute settlement procedures introduced unforeseen issues, including the concept of 'risk' which had to be assessed and allowed for in dispute hearings. A complaint of 'unfair' trade protection arising from quarantine or technical regulations required an assessment of the consequences of changing them to meet international standards, which would include an analysis of risk of disease or damage. The WTO is not equipped to assess scientific risk or to establish international standards, and now disputes include arguments about social, environmental and cultural risks too. This has placed severe pressures on dispute panels and the Appellate Body, and has exacerbated differences among members over interpretations of WTO agreements.

The WTO has also become a target for 'global civil society'. Since 1995, non-government organizations (NGOs) pursuing a range of environmental and social objectives in the international arena have attacked inter-governmental 
agencies, such as the WTO and OECD, declaring they are supra-national, probusiness and anti-democratic. The resulting demonstrations in Paris, Geneva, London and Seattle since 1998 have elicited very little response from governments. Such reluctance to confront the NGOs can only encourage them and weaken international agencies.

A more subtle challenge is occurring through new procedures made possible by Uruguay Round agreements intended to shore up the multilateral trading system. The dispute settlement process has developed into a quasi-legal process which is constructing a case-law approach to interpretations of WTO provisions. This creation of 'international law' by bureaucrats is welcomed by NGOs, many of which are led by lawyers. These new legal verdicts are exactly what the NGOs seek through environmental treaties, such as the Kyoto Protocol, Montreal Protocol, Biosafety Protocol and so on. Agreements under United Nations' auspices are declared to supersede national laws, and are used as standards with which to batter 'politically incorrect' governments into line. They provide a route to influence national policies without the hindrance of having to be democratically elected to national legislatures. Though many legal scholars deny that 'international law' is superior to national law - indeed, deny there is any such thing as international law - the acceptance of this approach by powerful NGOs confronts governments with a dilemma; to reject these 'treaty' laws and oppose NGOs, or to seek compromises which reduce sovereignty. Both require more courage than most OECD governments can find.

The case-law approach employed in the WTO dispute settlement process has become one focus for NGOs. Any panel report or Appellate Body decision that suits their interest is regarded as a 'law' by NGOs. Each dispute referred to a WTO panel interests NGOs, even if the volume of trade affected is paltry. In this process risk measurement, assessment and management are scrutinized, and if necessary challenged. If scientific evidence does not suit their interests, social or cultural risks are emphasized to achieve the desired outcome, and any inconsistent evidence rejected or ignored. Since the WTO Secretariat is not equipped to undertake risk analyses, the dispute panels have to rely on outside experts, though this still requires them to choose between alternative opinions. This is a far cry from GATT's negotiated settlements of disputes of earlier times.

The role of risk in international trade relations and in the interpretation of agreements has become a battleground for NGOs to undermine the international economic agencies, and indirectly national governments, under the guise of countering the dangers of globalization. Ironically, multilateral environmental agreements - just as much a part of globalization - are viewed positively. At the same time, the question of risk raises difficult technical problems which go beyond the political dimension. 


\section{WHAT IS RISK?}

Risk is evident in every aspect of life and it has to be taken into account at all levels of production, consumption, investment, leisure, sport and so on. Taking risk and overcoming it brings benefits; profits and growth, personal achievement, financial returns and so on. Current attitudes (probably drawn from economic prosperity and the welfare state) seek to minimize risk and suggest that any damage from taking risks is someone else's responsibility (the litigious society). Progress depends on prudent risk taking, and risk takers benefit from making correct judgements, because few human activities do not involve some degree of risk.

To understand the role of risk in economic and social decisions requires understanding of probabilities and alternative outcomes. Rejecting risk without some idea of probabilities of an event occurring, and the costs that may result from it, is to close opportunities unnecessarily.

Analysis of risk in international trade requires assessment of probabilities of different scientific and economic outcomes, followed by an assessment of the social consequences of alternatives. Only when all the evidence and evaluations are available to policymakers can decisions be made about managing risk. Evidently, this depends on perceptions of risk by the community. A risk-averse community would place low value on potential returns from a risky venture. Collective or social decisions are likely to be more risk-averse than individual decisions, and wealthy individuals are likely to be more risk-averse than poor ones.

In international agreements, participating countries may agree to harmonize standards of risk. This is most apparent in regional economic agreements (EU, NAFTA and so on) but harmonization is also present in some WTO agreements (TRIPs, GATS). Any compromise is likely to create conflicts with national policies in the more risk-averse countries. This causes problems over sovereignty, which becomes a reason for escape clauses and exceptions provisions in many agreements.

This volume explores aspects of risk with special reference to the WTO, where some national instruments to reduce risks may conflict with international trade rules. Quarantine regulations, technical/product standards and environmental legislation in some circumstances may conflict with trade rules and principles, and result in trade disputes. How should differences in attitudes to risk be resolved? Should international commitments override national regulations? In what circumstances might national preferences prevail? How should risk assessments be made and judged? How should differences in social perceptions of risk be taken into account?

The papers in this volume were presented at a seminar held at the Melbourne Business School in February 1999. That meeting brought together practition- 
ers and scholars from the areas of trade and risk management, from universities and business, from national government agencies and the WTO. The chapters are based on the invited presentations and remarks by discussants who were provided with the papers in advance. Several discussants' remarks have become chapters in their own right. The discussion proceeded under Chatham House rules, which preclude attribution of comments, but the flavour of these discussions has been distilled into the concluding chapter.

The range of papers indicates the many disciples and perspectives which are appropriate to the subject of risk and trade. There is inevitably a diversity of styles and approaches, as befits contributions from international lawyers, economists, political scientists, scientists and administrators.

\section{STRUCTURE OF THE VOLUME}

The papers presented at the seminar are under five headings, plus a concluding summary.

\section{Risk and the WTO \\ II. Managing risk in policymaking \\ III. Negotiating experience with risk \\ IV. National risks and quarantine standards \\ V. Managing biotechnology}

Part I comprises four chapters which explain how the WTO agreements deal inadequately with risk relating to trade and environmental considerations, and review the difficulties this has created in the dispute settlement process.

Gary Sampson, former Director for Trade and Environment, WTO Secretariat, notes in Chapter 1 that the WTO seeks to provide flexibility for national policies without allowing disguised barriers to trade. The comprehensive scope of the WTO means that risk in all its forms has become a controversial issue when it comes to interpreting agreements.

Sampson begins by explaining the narrow focus of the WTO's mandate on the environment. Once this is understood many environmental NGOs' complaints are put into perspective. The Committee on Trade and Environment (CTE) is concerned strictly with trade and trade effects of environmental policies, in the context of the WTO's agreements and trade rules. Risk enters into the work of the CTE because international environmental agreements can contain provisions on trade that conflict with WTO disciplines. In particular, efforts to get the precautionary principle incorporated into these treaties (for example, EU efforts in the Kyoto Protocol and the Biosafety Protocol) raise problems if trade discrimination results. Some instruments proposed for the 
Kyoto Protocol would require border tax adjustments and discrimination according to production processes that would not be GATT compatible. Controversies over interpretations of GATT article XX have been at the centre of the CTE negotiations since 1995. In the recent shrimp-turtle dispute, the Appellate Body appears to have shifted this interpretation to allow for environmental considerations under some circumstances. Immediate adoption of this decision by the US delegate to the Dispute Settlement Body (DSB) brought a significant change in WTO treatment of environmental policies.

WTO treatment of risk is important also in the context of the agreement on sanitary and phyto-sanitary policies (SPS) and, more broadly, the agreement on technical barriers to trade (standards) (TBT), where the adoption of international standards may produce arbitrary decisions which could affect trade but would impose economic and non-economic costs on countries. The Canadian complaint about Australian quarantine restrictions on imports of fresh, chilled and frozen salmon (salmon case) required assessments of risks arising from changes. Such cases of increasing risks may have farreaching consequences. These new Uruguay Round agreements emphasize the national treatment requirements in GATT article III. The TBT agreement was invoked in 1998 by the US and Canadian delegates against an EU proposal to regulate labelling of GM foods, which they regarded as an unnecessary technical barrier. If pursued, this would require assessment of scientific, economic, social and political risks. Each country may consider it necessary to conduct its own risk analysis. This would create complex problems for dispute panels. (The results from disputes that have been referred to panels are examined by Cottier and Pauwelyn.) Sampson concludes that the WTO function is to avoid unjustified impediments to trade. But do existing provisions give sufficient flexibility to address complex risk issues?

Sampson's chapter establishes the WTO framework for dealing with risk and identifies the relevant agreements. In Chapter 2, Neil Byron takes up the discussion as viewed by environmental lobbies. Green groups believe that the WTO impedes desirable environmental strategies and they would wish to transform the WTO into the guardian of the Earth's environment. This confrontation is one of the most dangerous because it could end up restoring trade protection and reducing environmental protection.

Byron agrees with Sampson that the WTO has no role in assessing scientific risk, especially when the environment is involved, and it should not arbitrate on acceptable levels of risk or on risk management. However, the WTO is responsible for assessing whether its trade rules are being flouted using risk as an excuse. The precautionary principle often features in such risk assessments. The European Commission (EC) has become a strong advocate of the precautionary principle in many international agreements including the recent Cartagena Protocol on Biosafety. The EC position leans towards social deter- 
mination of risk and political processes that play down scientific estimates of risk. (The EC has published a 'communication' on use of the precautionary principle, which is an appendix to this report.) Byron analyses this controversial approach and exposes ambiguities in alternative definitions of the precautionary principle that cause many problems. He concludes, like Sampson (and later, Nunn), that there is no general acceptance of this principle as international law.

Byron concludes that environmental groups seem to believe that trade measures administered by the WTO offer the best hope of enforcing their goals, and this accounts for the intensity of feeling generated against WTO rules requiring consistent and transparent procedures.

Chapters 4 and 5 describe experience with the dispute settlement process and the uncertainties that have arisen between panel reports and re-interpretations of evidence by the Appellate Body. Thomas Cottier has participated in several dispute panels and has wide experience in the interpretations of WTO agreements. Joost Pauwelyn is a WTO official dealing with trade disputes. Both focus on disputes brought under the SPS agreement.

Cottier separates scientific from social assessments of risk, and separates risk management from risk assessment, which is consistent with decisions by the beef-hormones panel. He calls for a suitable methodology for taking account of social and economic considerations in risk management, including social and political acceptance of risk, something not recognized in the SPS agreement. The need to adopt international standards has to begin with scientific evidence, as required by the SPS agreement. National authorities could be required to examine conformity of their measures with international standards to avoid disputes. Clarification of scientific interpretations, however, would help to eliminate contradictions between panel and Appellate Body reports. Trade remedies could be tightened by introducing compensation for delays in achieving international standards. Cottier acknowledges that conflicts in society over biotechnology products bring new problems and he calls for a review of the SPS agreement to take account of experience over the past five years.

Pauwelyn traces the procedures and the evolution of case law in three trade disputes conducted using the SPS agreement - EU-US beef-hormones, Japan-US agricultural products and Australia-Canada salmon. The 1999 review of the SPS agreement drawing on this experience raised some matters of concern but no changes to the text were recommended to the ministerial meeting by the DSB. The type of amendments suggested by Cottier open the whole agreement to renegotiation, which was regarded as too radical in the lead-up to the Seattle ministerial meeting. Moreover, the case-law approach allows an evolutionary process to interpretation of the SPS agreement and panel procedures. For example, the EU beef-hormones dispute established that risk assessment should be based on scientific evidence and not involve social or 
political values. Once a risk assessment is made, it is up to the member government to judge an acceptable level of risk and, if necessary, an appropriate non-discriminatory SPS measure (ALOP).

In many instances, the Appellate Body has reversed or qualified dispute panel decisions, which is causing confusions on interpretations and weakening the case-law approach. Adoption of dispute panel reports is delayed until an appeal has been held. When a decision is finalized by the DSB, implementation of the findings is invariably delayed. Decisions on compensation or retaliation create bad feeling. Whether trade sanctions against offenders are appropriate in terms of WTO principles on non-discrimination and trade liberalization is a fundamental question.

Part II on managing risk takes a broader view of risk assessment and risk management in policymaking. The three chapters in this part cover definitions and perceptions of risk, and how they affect government policies.

Marion Wooldridge is a quarantine expert in the UK Ministry of Agriculture and has given expert evidence to WTO dispute panels. In Chapter 6 she regards risk management as the key requirement of policymaking, to reduce uncertainties and anxieties in the community. Later she admits that risk taking is also the driving force for progress because risk takers earn high returns, but that definition is rather broader than her specific interest, which is quarantine - the protection of human, animal and plant health. If zero risk is not possible, how much risk is acceptable? This became a problem of perception, which Christine Deane later shows is a morass of alternative sources of information and opinion, complicated by competing interest groups and disinformation.

Wooldridge posits that the first question is, 'What is the acceptable level of risk?' This is exactly where dispute panels find themselves in the SPS cases. This 'judgement' will determine the safeguards necessary (ALOP). In a review of requirements of international risk management, Wooldridge assesses favourably the principles of the SPS agreement. The traditional approach to risk assessment was to gather information on hazards and the consequent risks, which could then be compared with expected benefits from an activity and alternative safeguards. Dramatic changes in dissemination of information have shifted the emphasis of this approach to concern about 'stakeholders'" attitudes, which complicates risk assessments and any proposed policies. Wooldridge examines the stakeholder position and risk communication in detail. The political clout of 'stakeholders' (especially in the EU) evidently complicates decision making, and once policymakers open their deliberations to such groups it becomes difficult to exclude any group, however extreme or irrelevant. Ultimately, all opinions cannot be satisfied.

In Chapter 7 Michael Nunn provides a very thoughtful and thorough chapter on risk analysis and identifies clearly the different stages in that process; risk 
assessment, risk management and risk communication. He relates risk analysis to trade and technical standards.

Nunn defines risk assessment as the identification of the risks or hazards, the assignment of probability of each risk and an estimation of the consequences of a risk. Quantifying risk poses many problems even when limited to scientific evidence, and difficulties of estimation have encouraged resorting to qualitative approaches in quarantine disputes. Moreover, variability in scientific risk assessment causes concern, particularly when associated with environmental problems. Nunn argues that sensitivity analysis can assist by showing that often only a few critical points significantly affect overall probabilities. However, where uncertainty occurs there are always advocates for the precautionary principle, which means a conservative approach to risk. Such approaches become especially difficult when quantitative assessments of risk consider economic and social factors as well as scientific evidence. He concludes that in future, trade disputes will require risk assessment by multidisciplinary teams.

Christine Deane reviews evidence on risk perceptions, which introduces the additional uncertainties of opinion and disinformation. Deane concentrates on public perceptions of risks from biotechnology which extend beyond scientific risk to incorporate social attitudes, personal values and education. Once again, the role of 'stakeholders' becomes significant.

By surveying public opinion polls, Deane is generally optimistic that new technology is acquiring more acceptance in OECD countries, but much scepticism still exists in these communities. Scientists and the general public have different perceptions of risk, and with social values dominating socially active groups ('civil society'), it means risk perceptions depend more on the characteristics of the public than on risk probabilities. This is revealed in public acceptance of biotechnology for medical purposes while it is rejected in GM foods.

With public opinion and 'stakeholders' becoming so significant in risk evaluation, the opinion formers in society become important. Surveys show that 'experts' (scientists, economists, bureaucrats) are not trusted. TV programmes, consumer organizations, NGOs and newspapers are thought more reliable. Consultation is regarded as one device to change public opinion in the EU, and establishing an effective independent regulatory system is also valuable (compare the US Food and Drug Authority (FDA) with food safety worries in Europe).

The third element that Deane identifies as significant in influencing public perceptions of risk is education. Consultation and dissemination of information are important, but education can be more fundamental. The concept of probability is not widely understood judging by media reporting of scientific results. Most people focus on personal effects should an identified risk materialize. A probability of infection arising from a vaccination of 1:1000 000 
dissuades some mothers from having a child vaccinated, but no weight is given to the 1:10 000 risk of contracting the disease without such protection. The same misunderstanding of probabilities is apparent in smokers. This suggests basic education is very important for public risk perception.

Part III introduces the politics of international negotiations. Aynsley Kellow (Chapter 9) explores the politics of risk and the balancing of conflicting interests in international negotiations. Kaye Dal Bon presents a history of extended OECD negotiations on reducing risks from lead. This experience indicates that low risk perceptions can differ and result in conflicting proposals, even when all the evidence is scientific.

Aynsley Kellow draws on extensive research on multilateral environmental agreements (MEAs). He divides risk analysis into four stages: hazard identification, risk estimation, risk evaluation and risk management. The first three are covered by risk assessment in Nunn's approach and Kellow combines risk management with risk communication. But Kellow focuses on socio-political factors which Nunn incorporates into risk assessment and emphasizes in risk communication. Kellow points out that in international negotiations there is a temptation to seek unanimity (or at least agreement) in science: a fault that could be levelled at the SPS agreement. But on environmental issues, the sociopolitical forces tend to be as significant as the scientific evidence: references are made to the Kyoto Protocol and the Basel Convention.

Kellow argues that attempting to keep socio-economic interests out of risk management at the international level is to invite the contamination of science by interests. Rather, the evaluative aspects of risks need to be explicitly included at the appropriate stage to enhance negotiated agreements. This would reduce the chance of measures being used as trade impediments.

Dal Bon's review of OECD negotiations on lead contamination in Chapter 10 is a valuable case study. It shows how mistaken perceptions can arise in measurement of lead levels under different circumstances. Happily European misperceptions of lead levels were corrected in these extended OECD negotiations. Other attempts to condemn chemical uses may not be properly constrained, causing potential damage from protection for false environmental reasons (for example, restricting use of dioxin in developing countries to control mosquitos may satisfy OECD environmentalists but it does not help developing countries to control disease).

Part IV draws on Australian experience with the SPS agreement to evaluate interactions between national policies and international agreements. The intensity of the quarantine debate in Australia over a broad range of import embargoes makes this a review with implications for many other countries.

In Chapter 11, Wilson and Gascoine (AQIS) review the contents of the SPS agreement and its relationships with other WTO agreements and international standards organizations. They go on to examine quarantine risk analysis in 
Australia after the Nairn review of Australian Quarantine (1996) and compare these procedures with obligations in the SPS agreement, including references to the salmon dispute proceedings. The authors conclude that the SPS agreement has been beneficial and the gain real. Ambiguities remain in the drafting, but clarifications from experience are preferable to a substantial re-negotiation of the present text.

Donald MacLaren (Chapter 12) undertakes an economic analysis of the SPS provisions in the context of bulk imports of feed grains into Australia in 1994. He casts doubt on the practicality of the SPS agreement because it assumes that scientific evidence is unambiguous and risk probabilities can be estimated. MacLaren argues that even if very small probabilities of damage exist, very high costs might occur. Governments are very sensitive to these, and unforeseen contingencies cannot be allowed for. All these considerations complicate national decisions on quarantine risks, while international assessments of these risks may place different weights on the risks and costs of outcomes.

Chapter 13 contains a business view of quarantine regulations. Lyall Howard acknowledges the AQIS assessment of the SPS agreement and the ambiguities and gaps that need to be clarified. Some Nairn report submissions indicated that uncertainties surround risk assessments and MacLaren's paper has formalized these problems in a theoretical analysis. The 1994 grains case analysed by MacLaren has provided new information on risks for future national assessments. Howard notes that a harmonized approach to quarantine regulation should benefit world trade, but the three chapters in this part also show a proper balance still has to be found between trade and SPS interests.

Part V introduces the controversial subject of genetically modified organisms (GMOs). Nancy Millis (Chapter 14) is Chair of Australia's Genetic Manipulation Advisory Committee and has had a distinguished career in microbiology. While acknowledging that proper testing of GM crops is necessary, Millis points out that much genetic engineering simply accelerates normal breeding within species that has been followed for decades (even centuries). Transgenic manipulation (splicing genes from different species) needs more careful monitoring but on the whole this is still in laboratories and strictly supervised. Testing of GM crops needs to be scrutinized, but opposing all GM plants on principle is irrational, especially when it is 'within species' rather than transgenic - and seems ridiculous when genetic engineering for medical purposes is welcomed.

Professor Millis explains the complicated procedures and committees being introduced in Australia to monitor and evaluate GMOs. The draft legislation, which has yet to be discussed in Parliament, constructs a pyramid of screening bodies and review committees to assess GMOs at the experimental stage and before release for experimental or commercial use. This is an example of regulatory mechanisms that are being prepared by most national governments. 
Robertson's Chapter 15, 'GM foods and global trade' draws attention to the major trade issues surrounding the GM foods issue. This was expected to form part of the general discussion of biotechnology in the new trade round. Interestingly, many of the risk issues and prejudices evident in WTO disputes are also present in the GM food debate.

The volume concludes with a summary of the main points raised during the seminar and some assessment of problems. Globalization of economic activity and the adoption of a system of trade rules to facilitate integration have highlighted problems of risk evaluation, assessment and management. The papers here attempt to clarify some of the issues arising in the growing controversy over risk. The final chapter considers the issues surrounding risk management as globalization and the counterforce of 'civil society' confront. 
David Robertson - 9781843762997 Downloaded from PubFactory at 04/26/2023 10:24:08AM via free access 